\title{
En respuesta a "Vacunación antigripal y protección del paciente crítico: responsabilidad de los profesionales sanitarios"
}

Reply to "Influenza vaccination and critical patient protection: responsability of healthcare workers"

$\mathrm{J}_{\text {Marin-Corral }}^{\mathrm{ab}}$, Muñoz-Bermúdez $\mathrm{R}^{\mathrm{ab}}, \mathrm{F}$ Álvarez-Lerma ${ }^{\mathrm{abc}}$

\footnotetext{
${ }^{a}$ Servicio de Medicina Intensiva, Hospital del Mar de Barcelona, Barcelona, España.

${ }^{\text {b }}$ Grupo de Investigación en Patología Crítica (GREPAC), Instituto Mar de Investigaciones Médicas (IMIM), Barcelona, España.

${ }^{\mathrm{b}}$ Universitat Autònoma de Barcelona (UAB), Barcelona, España
}

Sr Editor,

En primer lugar agradecer a los autores de la carta " Vacunación antigripal y protección del paciente crítico: responsabilidad de los profesionales sanitarios" su interés y referencia a nuestro artículo.

La infección por Influenza es la enfermedad prevenible mediante vacunación más común en nuestro medio (1), ya que es una medida de salud pública particularmente efectiva que ha demostrado prevenir la enfermedad, los ingresos hospitalarios $y$ consecuentemente la mortalidad por dicha infección $(2,3)$.

Aunque todavía pocos trabajos aportan datos al respecto ya se ha descrito la infección por virus Influenza adquirida en el hospital o nosocomial. Un reciente trabajo de nuestro grupo (4) mostró una incidencia del 9,3\% de infección por gripe A adquirida en el hospital (aparición de síntomas a partir del $7^{\circ}$ día de ingreso) en una cohorte de 2.421 pacientes graves ingresados en la Unidad de Cuidados Intensivos. Los pacientes con gripe A nosocomial presentaban un perfil clínico, una severidad al ingreso en $\mathrm{UCl}$ y unos requerimientos terapéuticos diferenciados respecto a los pacientes con infección adquirida en la comunidad y la adquisición intrahospitalaria se relacionó de manera independiente con la mortalidad. 
Este hallazgo refuerza el mensaje que los autores indican en el título de su carta. Nosotros compartimos su opinión sobre la importancia de la vacunación en los profesionales sanitarios para evitar la transmisión de la infección. Coincidimos en que la baja cobertura vacunal de dicho colectivo, y en especial en las $\mathrm{UCl}$, debe ser abordado por los responsables de establecer las políticas sanitarias siguiendo las recomendaciones de la evidencia científica y de los comités de seguridad y salud laboral locales de cada centro. En este sentido en la UCl de nuestro hospital, y gracias a las campañas institucionales dirigidas por el Servicio de Seguridad Laboral, se ha registrado un incremento en las tasas de vacunación antigripal del personal sanitario, que han pasado del 29,5\% en el año 2015 al 38,1\% en el año 2017, en especial entre el personal médico (72,2\%).

En las $\mathrm{UCl}$ y en el resto de unidades de hospitalización las recomendaciones deberían extenderse más allá de la vacunación del personal sanitario y ampliarse a todas las personas que entran en contacto con los pacientes, incluyéndose a sus familiares. Las precauciones a tomar deberían incluir evitar el contacto de visitantes o de personal sanitario con clínica gripal con los pacientes, la utilización de mascarillas durante los periodos epidémicos y el cumplimiento de la normativa de higiene de manos antes y después del contacto con el paciente.

La prevención de la transmisión del virus Influenza en los hospitales y especialmente en las áreas de críticos, debe ser un objetivo prioritario. La vacunación del personal sanitario continúa siendo una de las estrategias clave en este sentido e implementar las medidas que han demostrado ser más efectivas para incrementar la tasa de vacunación en este colectivo (obligatoriedad o cumplimentación de una declaración de rechazo de la vacuna) podría mejorar la situación actual (5).

\section{Bibliografía:}

1. Fiore, A.C.; Bridges, C.B.; Katz, J.M.; Cox, N.J. Inactivated influenza vaccines. In Vaccines, 6th ed.; Plotkin, S.A., Orenstein, W.A., Offit, P.A., Eds.; Elsevier: Philadelphia, PA, USA, 2012; pp. 257-293.

2. Advisory Committee on Immunization Practices; Centers for Disease Control and Prevention (CDC). Immunization of health-care personnel: Recommendations of the 
Advisory Committee on Immunization Practices (ACIP). MMWR Recomm. Rep. 2011, $60,1-45$.

3. WHO Regional Office for Europe. WHO Regional Office for Europe Recommendations on Influenza Vaccination during the 2015/2016 Winter Season. 2015. Available online: http://www.euro.who.int/en/health-topics/communicablediseases/influenza/publications/2018/recommendations-on-influenza-vaccinationduring-the-20182019-winter-season-2018 (accessed on 26 December 2018).

4. Álvarez-Lerma F, Marin-Corral J, Vilà C, Masclans JR, Loeches IM, Barbadillo S, González de Molina FJ, Rodriguez A. H1N1 GETGAG/SEMICYUC Study Group. Characteristics of patients with hospital-acquired influenza A (H1N1)pdm09 virus admitted to the intensive care unit. J Hosp Infect 2016; 95(2): 200-206.

5. Lytras T, Kopsachilis F, Mouratidou E, Papamichail D, Bonovas S. Interventions to increase seasonal influenza vaccine coverage in healthcare workers: A systematic review and meta-regression analysis. Hum Vaccin Immunother 2016; 12(3):671-81. 